\title{
Analytical Comparison of Continuous Subcutaneous Insulin Infusion and Multiple Daily Injections in Children and Adolescents with Type I Diabetes Mellitus
}

\author{
Aladin A Siddig ${ }^{1}$, Thi Diem My “Priscilla" Bui ${ }^{1}$, Dean R Readon ${ }^{1}$, Monica Ven ${ }^{1}$, Zachary Bailes ${ }^{1}$, Jacob Hefner ${ }^{1}$, Aaron Gillig ${ }^{1}$, \\ Divansh Singh ${ }^{1}$, and Kwame G Yeboah*
}

${ }^{1}$ University of Charleston School of Pharmacy, Charleston WV, United States

${ }^{2}$ Harding University College of Pharmacy, Searcy, AR., United States

*Corresponding author: Kwame G Yeboah, Harding University College of Pharmacy, Searcy, AR. 72149, USA, Tel: +(501) 279 5391, Fax: +(501) 279

5202. E-mail: gyeboah@harding.edu

Received: 17 Jun, 2020 | Accepted: 01 Jul, 2020 | Published: 10 Jul, 2020

Citation: Siddig AA, Bui TDMP, Readon DR, Ven M, Bailes Z, et al. (2020) Analytical Comparison of Continuous Subcutaneous Insulin Infusion and Multiple Daily Injections in Children and Adolescents with Type I Diabetes Mellitus. J Drug Res Dev 6(2): dx.doi.org/10.16966/2470-1009.154

Copyright: (C) 2020 Siddig AA, et al. This is an open-access article distributed under the terms of the Creative Commons Attribution License, which permits unrestricted use, distribution, and reproduction in any medium, provided the original author and source are credited.

\begin{abstract}
Introduction: Continuous subcutaneous insulin infusion (CSII) is a form of insulin administration for patients with type I diabetes mellitus (T1DM) that was introduced as a means of stimulating normal plasma insulin fluctuations and provide better metabolic control that is better than multiple daily insulin injections (MDI). The purpose of this study was to determine the effect of CSII as compared to MDI in the treatment of T1DM in children and adolescent below 20 years of age.

Methodology: This study is a meta-analysis examining the quality of glycemic control in patients receiving continuous pump therapy compared to those receiving multiple daily injections. Multiple clinical studies/journal articles that compared the use of CSII to MDI in insulin dependent children and adolescents were examined for information on blood glucose and hemoglobin A1c (HbA1c).

Conclusion: Under proper treatment of T1DM, there are no significant differences between CSII and MDI therapies. However, it was found that CSII had the potential to better manage T1DM in cases of young children with erratic diets and activity level, as many patients with T1DM find it difficult to reach their goal HbA1c levels despite persistent efforts. Moreover, patients receiving CSII were found to have a decreased incidence of postprandial hyperglycemia. Thus, CSII can decrease the rates of glycemic irregularities if T1DM patients are incapable of achieving glycemic control with MDI. Overall, both MDI and CSII should be considered when deciding which treatment to use in a patient with T1DM.
\end{abstract}

Keywords: Type 1 Diabetes; CSII; MDI; Insulin; HbA1c; Glycemic control; Blood glucose

Abbreviations: T1DM=Type 1 Diabetes Mellitus; HbA1c=Hemoglobin A1c; CSII=Continuous Subcutaneous Insulin Infusion; MDI=Multiple Daily Injections

\section{Introduction}

Type I diabetes mellitus (T1DM) is an autoimmune defect associated with beta-cell destruction in the pancreas. As a result, the individual suffers from absolute insulin deficiency and becomes indefinitely dependent on administration of insulin to avoid insulindeficiency-related complications such as cardiovascular disease [1]. T1DM has become one of the most common chronic childhood diseases, and its incidence has doubled over the past two decades [2]. The prevalence of diabetes mellitus (type I and type II) is expected to increase to 439 million people by 2030 [3]. According to the SEARCH for Diabetes in Youth Study, approximately 18,000 children and adolescents younger than 20 years of age are diagnosed with T1DM annually with the highest rate in non-Hispanic Whites ${ }^{4}$.Strikingly, while the reported incidence of T1DM was about 21 per 100,000 in all races it was 26 per 100,000 among Non-Hispanic Whites [4]. This is the largest ethnic group in the Americas and Europe.
Furthermore, mismanagement of T1DM has been found to have a number of issues specifically associated with fluctuation in insulin levels that lead to acute complications of the resulting hyper and/ or hypoglycemia. Hyperglycemia is defined as a condition in which a patient's blood sugar is above $149 \mathrm{mg} / \mathrm{dL}$. This occurs most often when an individual fails to administer sufficient amount of insulin after a meal, but can also occur during strenuous exercise and hyperactivity associated with children and adolescents [5]. Classic symptoms of hyperglycemia are polydipsia, polyuria, weakness, fatigue, anxiety, and vision impairment. If left unattended to for long period of time, hyperglycemia could lead to serious metabolic crisis including diabetic ketoacidosis (DKA) and hyperosmolar hyperglycemic state (HHS); conditions responsible for more than 500,000 hospital days per year [6]. On the other hand, hypoglycemia is a condition in which a patient's blood glucose drops below 70 $\mathrm{mg} / \mathrm{dL}$. Hypoglycemia is characterized by confusion, tremors, 
diaphoresis, hunger, or in severe cases, unconsciousness and death. Hypoglycemia likely occurs due to excessive insulin administration or erratic consumption of carbohydrate-rich foods and is a lifethreatening complication that requires immediate treatment [7]. Other microvascular complications of insulin fluctuation include development of peripheral neuropathy, nephropathy and retinopathy. As such, improved glycemic control as a result of reduction in the fluctuation of insulin levels, has been the leading solution for these problems $[8,9]$.

Currently, two options for insulin delivery in patients with T1DM are continuous subcutaneous insulin infusion (CSII) and multiple daily injections (MDI). MDI has been the mainstay of treatment in adults, children, and adolescents, but CSII is starting to become a more prevalent option [10]. CSII is a portable pump therapy, usually the size of a cassette player, which is attached to the patient's body. Insulin is delivered continuously through a catheter port that must be changed every 7-10 days, and can be a cause for compliance issues [11]. CSII allows flexible adjustments in insulin dosage based on a variety of factors such as insulin-to-carbohydrate ratio and activity levels, resulting in improvements in glycemic control and clinical outcomes. This method has been shown to produce a patient satisfaction rate of $86 \%$ due to its self-management component [12]. Some patients prefer CSII from fear of hypoglycemia since it allows the patient to be more cognizant of their levels and how much they're injecting $[13,14]$. Furthermore, the improvement in pump technology has made the system more user-friendly and has led to a radical increased in CSII use in children [15]. Alternatively, MDI requires multiple needle injections that must be administered subcutaneously prior to meals and snacks throughout the day. MDI also requires the patient to dial up an additional amount of bolus insulin to cover carbohydrate consumption [16,17]. Moreover, patients receiving MDI therapy are to rotate their injection site for every injection in order to avoid bruising and lipohypertrophy [18]. Repeated injections have also been shown to be a possible cause of insulin allergies, and CSII has been preferred in this situation [17]. However, CSII has the potential drawback of pump malfunction that can lead to sever adverse events [19].

This meta-analysis examines the effectiveness of CSII and MDI in terms of glycosylated hemoglobin (HbA1c) levels. The HbA1c levels measure the average amount of agglutinated glucose on an individual's erythrocytes, over a 2 to 3 month period. According to the American Diabetes Association 2018 guidelines, target HbAlc for T1DM is less than 7\% [20]. Therefore, an $\mathrm{HbAlc}$ level of $7 \%$ or below was the benchmark for effectiveness in this study.

\section{Methods}

A literature search using databases such as PubMed/Medline Plus and Google Scholar was performed to gather qualified articles that are related to the comparison of CSII and MDI. To be included, the original articles had to be peer-reviewed, written in English, and discussed about either CSII or MDI usage in T1DM patients. Each article then was examined and analyzed and the applicable data were collated.

\section{Statistical Analysis}

The required parameters of comparative glucose level variability, metabolic outcomes, HbAlc of all the publications used in this metaanalysis were analyzed using Analysis of Variance (ANOVA) and paired $\mathrm{t}$-test by the various authors of the pulled publications. A P value of $\leq 0.05$ was considered to be the threshold of statistical.

\section{Results}

Overall, the data reviewed showed that CSII and MDI have similar efficacy in terms of reducing the incidence of hyperglycemia with no significant differences in pre-meal hyperglycemia and overall hyperglycemia for patients who adhered to their treatments $[15,21$ 24]. However, CSII was found to be slightly more effective with lower rates of postprandial glucose excursions and reduced HbAlc levels after 3 months of therapy $(p<0.007)[16,21]$. Moreover, a study done by Little SA, et al. on 96 participants randomized to receive CSII or MDI found significantly higher treatment satisfaction with CSII ( $\mathrm{P}=0.0003)$ [25]. Yet, CSII is also associated with higher incidence of morning hypoglycemia, although the statistical difference was deemed to be insignificant [16].

\section{Pre-pump and Post-pump CSII glucose profile}

Figure 1 is a comparison glucose profiles of moderately controlled adolescent patients before and after initiating CSII therapy [16]. As the figure shows, post-pump CSII had significantly improved mean hourly glucose levels over a 24-hour period $(\mathrm{p}<0.001)$ than the pre-pump CSII period. The specific changes in postprandial glucose measures pre- and post-pump respectively were: 349,24 vs. $267,16 \mathrm{mg} / \mathrm{dL}$ for breakfast ( $\mathrm{p}<0.003) ; 340,16 v s .217,20 \mathrm{mg} / \mathrm{dL}$ for lunch $(\mathrm{p}<0.003)$; and average post-dinner values reduced by $22 \%$ after 3 months of using CSII $\mathrm{p}<0.04)$ [16].

\section{Comparison of HbA1c in CSII and MDI}

Figure 2 shows the overall HbA1c patterns in both CSII and MDI groups over 24 months in newly diagnosed children of ages 7 to 17 years that were enrolled in a randomization study within 3 weeks of diagnosis, and with an average of 12 days after diagnosis. Throughout the study, all the patients received a similar percentage of their daily insulin as a bolus following mealtime [15]. As the figure 2 shows, both delivery methods were found to lower $\mathrm{HbAlc}$. At the beginning of the study, patients designated to receive CSII had an average $\mathrm{HbAlc}$ of $8.2 \pm 0.4 \%$, and those receiving MDI had an average HbAlc of 8.4 $\pm 0.5 \%$. At the conclusion of the 24 -month study, the CSII treatment produced an average $\mathrm{HbA1c}$ level of $6.5 \pm 0.4 \%$, while the MDI had an average level of $6.7 \pm 0.5 \%$.15There was no significant difference at any of the study time points between CSII and MDI groups $(p=0.66)$. Table 1 is a numerical representation of figure 2, expressing $\mathrm{HbAlc}$ values of participants at zero month (start of the study), as well as at

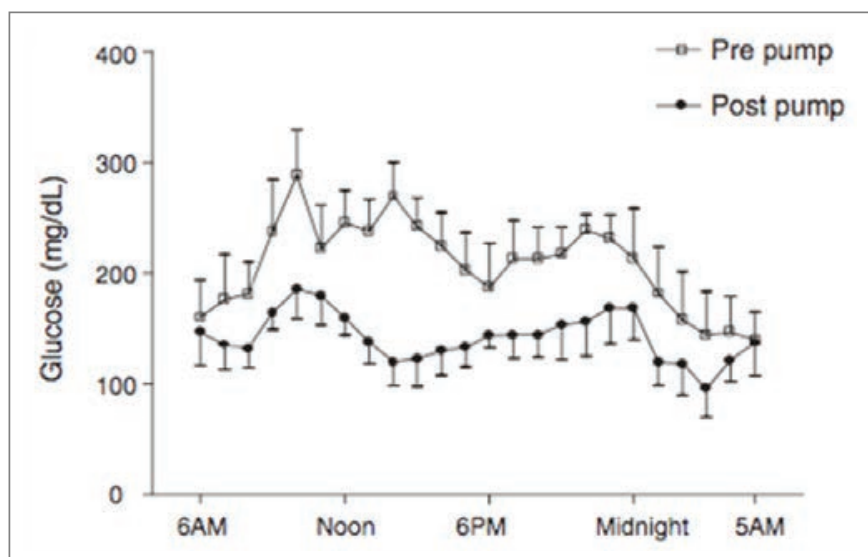

Figure 1: Interstitial glucose concentrations measured every $5 \mathrm{~min}$ over a 3-day period with an average of 900 readings. Mean hourly 24-h glucose sensor profile on all subjects before and after continuous subcutaneous insulin infusion. (Reused with permission from [16]). 


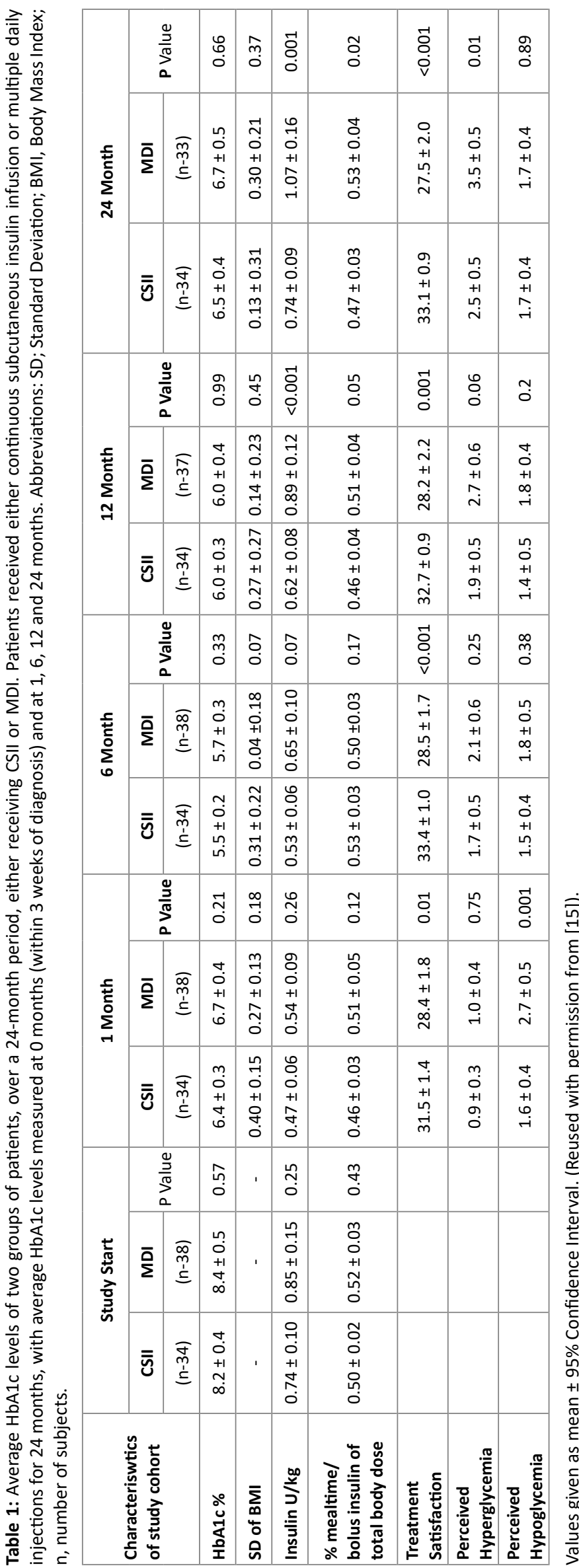

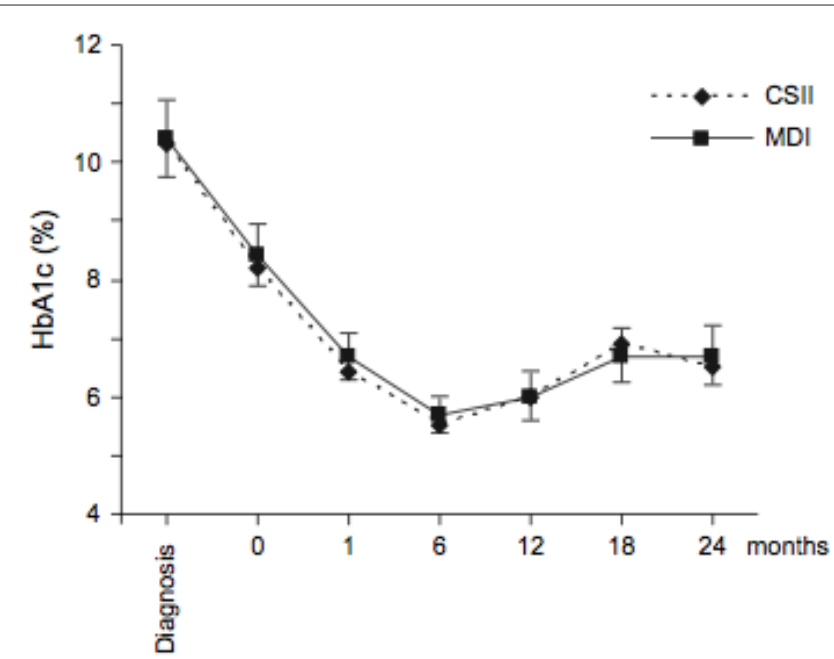

Figure 2: Average $\mathrm{HbA1c}$ levels of patients using CSII versus MDI therapy over a 24-month period. HbA1c levels during the study period. Values are presented as mean +/- 95\% confidence interval. The values for the CSII group are presented as black diamonds with a dotted line. The values for the MDI group are presented as black squares with a solid line. (Reused with permission from [15]).

$1,6,12$ and 24 months [15]. At zero months, patients receiving CSII had an average $\mathrm{HbAlc}$ of $8.2 \pm 0.4 \%$, and those receiving MDI had an average $\mathrm{HbAlc}$ of $8.4 \pm 0.5 \%$. At one month, the average $\mathrm{HbA1c}$ levels decreased to $6.4 \pm 0.3 \%$ (CSII) and $6.7 \pm 0.4 \%$ (MDI). At 6 months, the average $\mathrm{HbA1c}$ levels further decreased to $5.5 \pm 0.2 \%$ (CSII) and $5.7 \pm$ $0.3 \%$ (MDI). From the 12thmonth onwards, the HbAlc levels started ticking up for both methods of administration. The average $\mathrm{HbAlc}$ levels at the $12^{\text {th }}$ month increased slightly to $6.0 \pm 0.3 \%$ (CSII) and $6.0 \pm 0.4 \%$ (MDI). At the conclusion of the study (24 months), the average $\mathrm{HbAlc}$ levels increased again to $6.5 \pm 0.4 \%$ (CSII) and $6.7 \pm$ $0.5 \%$ (MDI) [15].

\section{Glucose level variability}

Figure 3 shows a report on the glycemic variability study between two patients, each using both CSII and MDI on different days [26]. The glucose level variability was determined by the ratio of the standard deviations to the means of glucose measurements. On the basis of glucose profile, the unstable variance was defined as greater than $30 \%$. The figure 3 shows that patient 1 experienced greater variance in glucose levels during CSII, whereas patient 2 achieved stable glucose levels using CSII, and sporadic glucose levels using MDI [26]. Table 2 shows no significant performance sensor performance in between CSII and MDI ( $p=0.30)$ thus there were no intrinsic biases in the of performance of the equipment used.

\section{Comparison of metabolic outcomes}

Figure 4 is age-adjusted HbAlc data from a study of 454 children with T1DM divided into CSII (231 participants) and MDI (223 participants) groups. The figure shows that CSII lowered HbAlc significantly greater than MDI. The average HbAlc level in the MDI group was $7.98 \pm 1.38$, as compared to an average HbAlc levels of $7.56 \pm 0.97$ the CSII group ( $\mathrm{p}=0.002)$ [27]. The variability in metabolic control as shown in Figure 5, was also significantly slightly better in the CSII group with a standard deviation (SD) of $0.73 \pm 0.45$ as compared to $0.84 \pm 0.54$ in the MDI group $(p=0.049)$ [27]. This $p$-value is borderline and therefore, it is not justifiable to conclude that one group 

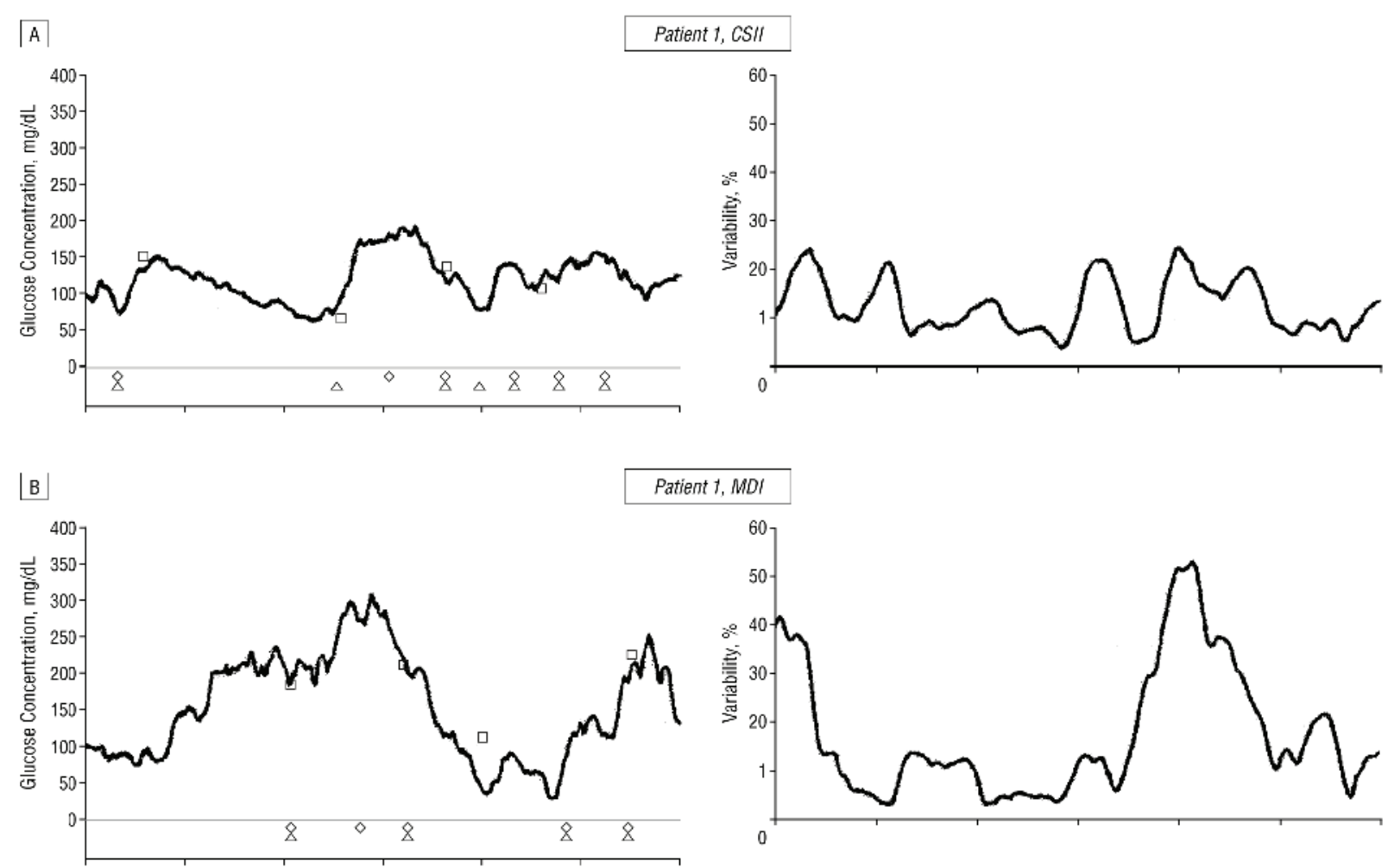

Patient 1, MDI
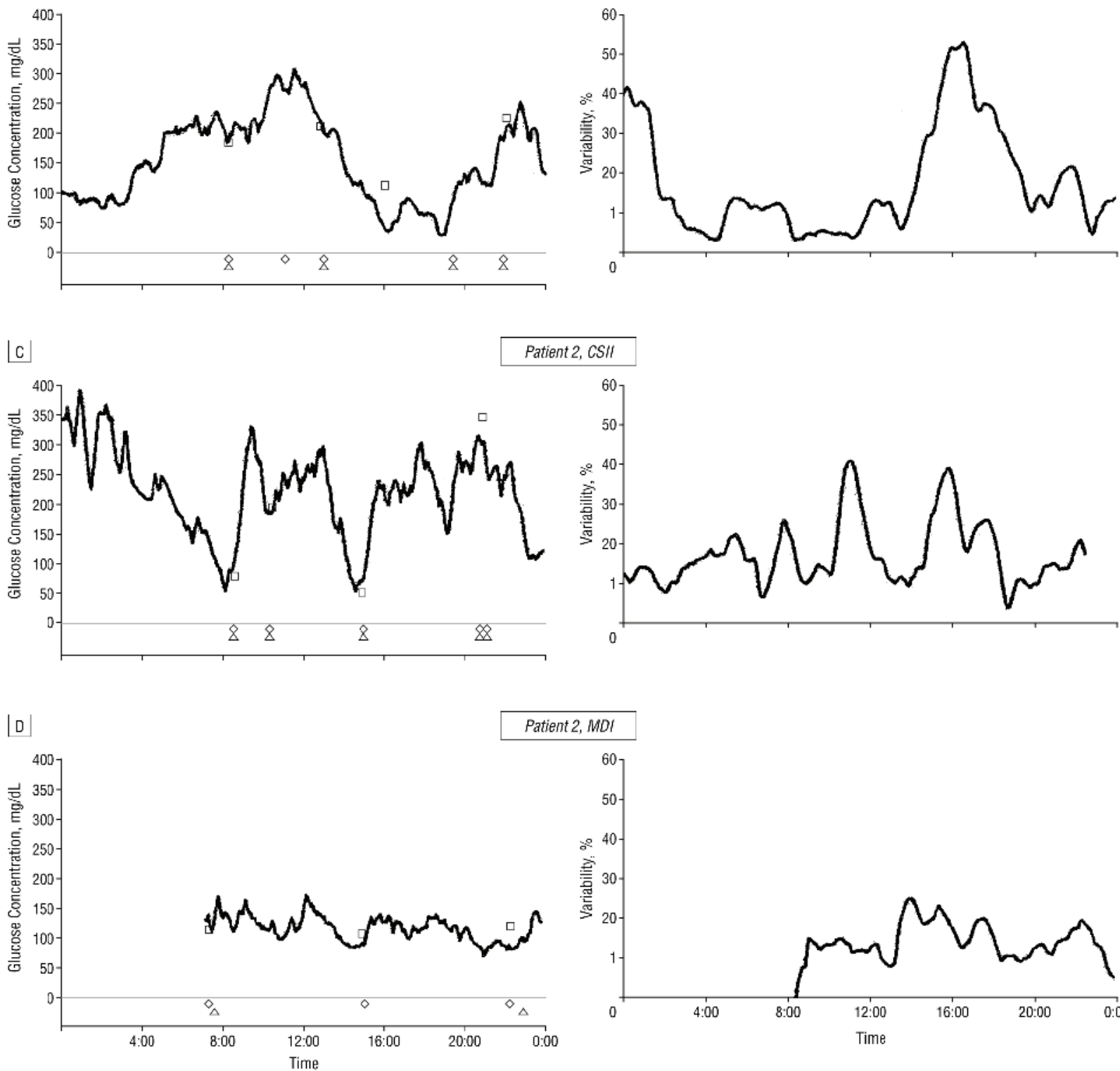

Figure 3: Administration of both CSII and MDI therapy to patients on different days, measuring effectiveness of therapy, as related to compliance. Representative 24-hour glucose sensor tracing obtained from 2 patients during continuous subcutaneous insulin infusion and multiple daily injections. The triangles represent daily events (insulin injections, hypoglycemia, exercise, etc.) The squares represent self-blood glucose measurements, using a glucometer. (Reused with permission from [26]) 
is superior to the other. However, the percentile comparison of relative improvement of $\mathrm{HbAlc}$ was significantly better in the CSII group with the median percentile equal to $45 \%$ with the Interquartile Range (IQR) of $24-68 \%$ and $58 \%$ with IQR of $29-81 \%$ for MDI group [27]. Furthermore, the percentage of patients that reached the therapeutic goal of less than $7 \% \mathrm{HbAlc}$ in the CSII group and the MDI group were $32.9 \%$ and $25.7 \%(\mathrm{p}=0.001$ ) respectively [27]. The data in this study, therefore, showed a superior outcome with CSII over MDI.

\section{Discussion}

The clinical studies gathered for this meta-analysis support the inference that with proper management of T1DM, there is no statistical difference between the use of CSII and MDI therapy with regards to blood glucose control. The CSII pump therapy had a better incidence of compliance in children and adolescents, which was why it was found to manage glucose levels better in one cohort of patients studied. External factors contributing to that study were the variability in each patient's diet and exercise [21].

Figure 1, from the study by Heptulla RA, et al. [16], depicts a clear control of blood glucose with CSII throughout the day, with the exception of a morning spike. This improvement was a result of an attenuation of postprandial blood glucose with CSII. In line with this finding, a study by Litton J, et al. [28], found that average HbA1c levels declined significantly with initiation of CSII therapy in preschool children (pre-CSII 9.5, 0.4\% vs. post-CSII 7.9, 0.3\%). The morning spike demonstrated in Figure 1 could be attributed to an early-morning increase in blood sugar, also known as the dawn phenomenon [16]. In the early morning, the human body will increase the levels of counter-regulatory hormones including growth hormone, cortisol, and catecholamine. The release of these hormones, accompanied by gradual elimination of basal insulin from our body system, cause patients to experience an increase in blood glucose [19]. Studies by Bouchonville $\mathrm{M}$, et al. [29] reported that owing to unpredictable nature of the dawn phenomenon, CSII is ineffective in correcting it. This phenomenon, however, can be corrected by injecting a rapidacting insulin before breakfast, or adjusting the time and/or dosage of basal insulin if found to be a severe problem.

Figure 2, from the study by Skogsberg L, et al. [15], showed the average $\mathrm{HbAlc}$ levels of patients receiving either of the two therapies decrease in a similar pattern. It was determined that when patients were less compliant with their treatment schedule, CSII continued to facilitate the delivery of insulin [15]. At the 6-month period of the

Table 2: Glucose monitoring sensor performance*.

\begin{tabular}{|l|c|c|c|c|c|}
\hline \multicolumn{1}{|c|}{ Variable } & Total & Range & CSII & MDI & P Value + \\
\hline Correlation, $\boldsymbol{r}$ & $089(007)$ & $0.70-0.99$ & $0.85(0.13)$ & $0.88(0.07)$ & 0.30 \\
\hline Absolute difference, $\%$ & $18.8(6.0)$ & $9.0-34.0$ & $20.1(7.8)$ & $18.7(6.1)$ & 0.22 \\
\hline No. of nights recorded $\neq$ & $2.6(0.6)$ & $1.0-3.0$ & $2.6(0.6)$ & $2.6(0.6)$ & 0.44 \\
\hline No. of Days recorded & $2.6(0.7)$ & $1.0-3.0$ & $2.7(0.5)$ & $2.6(0.7)$ & 0.48 \\
\hline
\end{tabular}

Glycemic pattern detected by Continuous Subcutaneous Glycose Sensing in children and adolescents with Type 1 Diabetes Mellitus treated by CSII vs. MDI. (*Data are given as mean (SD). Correlation and absolute difference are between point-to-point paired continuous glucose monitoring system and self-blood glucose measurement readings. + Significance of differences between CSII and MDI. $\neq$ The sensor was applied for 3 consecutive days and nights. Days were defined as 7 AM to 10 PM and nights as 10 PM to 7 AM). Reused with permission from [26].

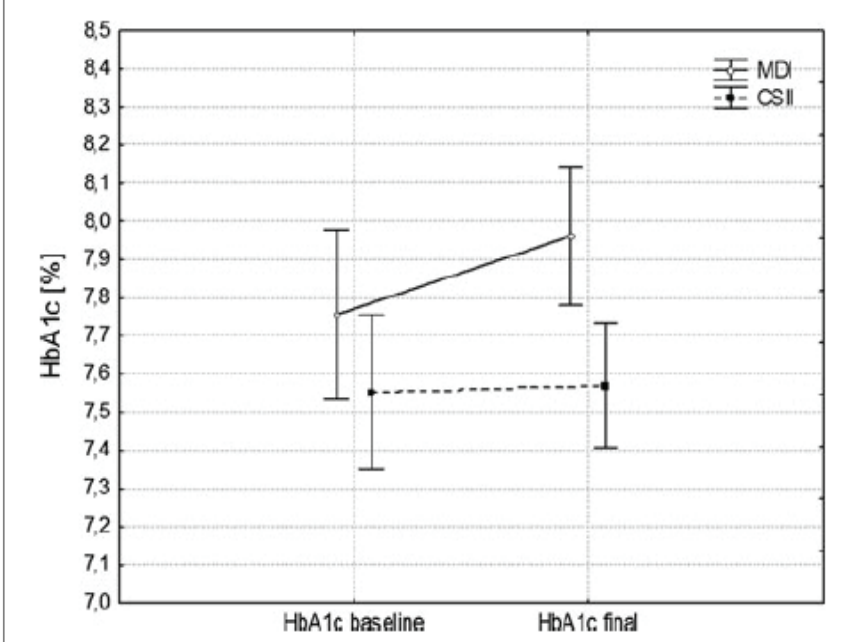

Figure 4: Differences in age-adjusted glycated hemoglobin (HbA1c) levels at baseline and at the end of the observation period in patients treated with multiple daily injections (MDI) or continuous subcutaneous insulin infusion (CSII). The difference between MDI and CSII-treated patients was significant at the end of the observation period $(P=0.01)$. Data are depicted as means with $95 \%$ confidence intervals. (Reused with permission from [27]).

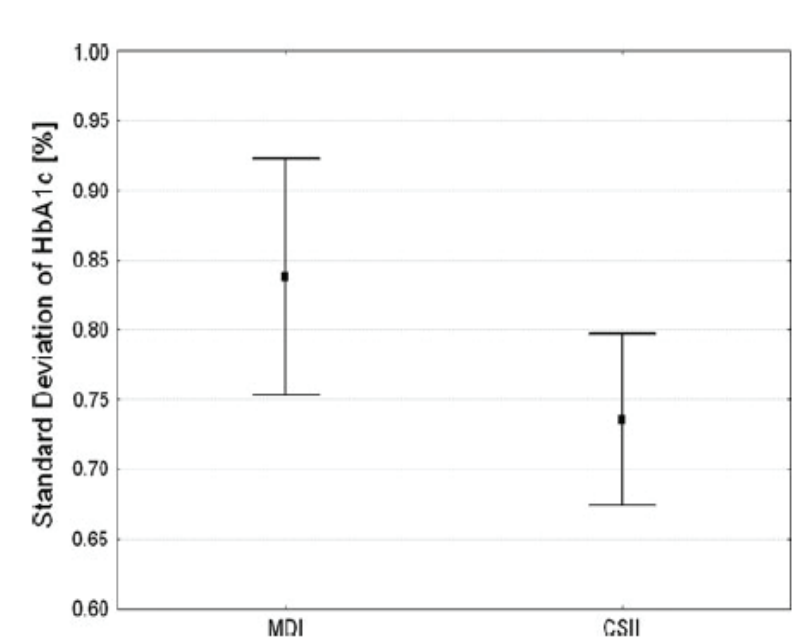

Figure 5: Differences in standard deviation of glycated hemoglobin levels in the studied groups. The difference between the multiple daily injections (MDI) and subcutaneous insulin infusion (CSII) groups was of borderline statistical significance $(P=0.049)$. Data are depicted as means with $95 \%$ confidence intervals. (Reused with permission from [27]). 
study, there was a prominent drop in patients'HbAlc levels followed by a slight increase in the subsequent months [15]. This is due to what is known as the "honeymoon" phase, or the period over which the patient's body is readjusting to the new routine of insulin therapy. Once the body becomes accustomed to the new therapy, it would develop insulin tolerance and would likely require a slight increase in insulin dosage to compensate for carbohydrate intake. Following this slight increase, the HbAlc levels plateaued again [15]. Table 1 further confirmed this observation with comparable average HbAlc in both treatment groups. Nonetheless, Figure 2 also showed that CSII therapy had an advantage in the maintenance of postprandial hyperglycemia, thus confirming previous study findings. At the end of the study, MDI had an average hyperglycemia incidence rate of 3.5 , while CSII therapy had an average rate of 2.5 [15]. Overall, the data showed no significant differences in metabolic control between the treatment groups. Thus, the study found that with proper adherence to insulin administration, either CSII or MDI can be a sufficient form of treatment in patients with newly diagnosed T1DM [15]. In line with this outcome, a study by Pozzilli P, et al. [30], found no preference between the two methods of administration in effectiveness. However, the lack of metabolic difference may be offset by the short time of study period of only one year, and undefined target HbAlc. A longitudinal study by Dost A, et al. [31] highlighted that children with T1DM may undergo remission phase within the first three years of diagnosis that may last $0.74,0.77$ years on average.

Figure 3 depicts data related to two patients who participated in a study over the course of one day, on two separate occasions. On the first day, each patient used CSII therapy, and on the second day each patient administered MDI. Patient 1 maintained a steady blood glucose level throughout the day while on MDI therapy. But, when using CSII therapy, the patient experienced varying blood glucose levels. Conversely, patient 2 exhibited more consistent blood glucose level with CSII, but more variance with MDI [26]. This supports the evidence that the success of each therapy is greatly dependent upon the compliance of the patient. Each therapy, when used correctly, can be a successful regimen of insulin administration.

In the Fendler W, et al. [27] three-year study, CSII showed better metabolic outcomes and slightly better metabolic control variability (Figures 4 and 5). However, the group found that this effect did not translate into the risk of acute hospitalization and the rates of hospitalization due to acute hospital visits did not differ between the CSII and MDI groups. The non-random allocation of patients to the groups is a limitation and a potential bias that study. The other confounding factor might have been the educational measures put in place during the switching phase [27].

\section{Conclusion}

These studies provide valuable information regarding insulin delivery options for children and adolescents with T1DM. Some previous trials, such as de Beaufort $\mathrm{CE}$, et al. detected more considerable glycemic improvements with CSII than MDI [32]. However, most studies supported the benefits of using either MDI or CSII to control glycemic variabilities as long as patients are compliant with the treatment. One common advantage of using CSII shown in many trials is that CSII requires less insulin dosage to achieve similar $\mathrm{HbAlc}$ values as compared with MDI [20]. Even when using the same insulin for both methods, mean insulin doses are still significantly lower with CSII than with MDI (38.5, 9.8 units/day vs. 47.3, 14.9 units/day) in the study by Hanaire-Broutin $\mathrm{H}$, et al. [33]. As a result, patients with T1DM might more easily achieve stricter target HbAlc with CSII, and thereby would help reducing the risk of retinopathy and nephropathy in the long term [34]. Therefore, future studies are needed to look at this perspective in depth.

\section{Consent for Publication}

Not applicable.

\section{Conflict of Interest}

The authors declare that there is no conflict of interest, financial or otherwise.

\section{Acknowledgements}

Declared none.

\section{References}

1. Matteucci E, Giampietro O, Covolan V, Giustarini D, Fanti P, et al. (2015) Insulin Administration: Present Strategies and Future Directions for a Noninvasive (Possibly More Physiological) Delivery. Drug Des Devel Ther 9: 3109-3118.

2. Hovorka R, Allen JM, Elleri D, Chassin LJ, Harris J, et al. (2010) Manual Closed-Loop Insulin Delivery in Children and Adolescents With Type 1 Diabetes: A Phase 2 Randomised Crossover Trial. Lancet 375: 743-751.

3. Moser EG, Morris AA, Garg SK (2012) Emerging Diabetes Therapies and Technologies. Diabetes Res Clin Prac 97: 16-26.

4. Mayer-Davis EJ, Dabelea D, Lawrence JM (2017) Incidence Trends of Type 1 and Type 2 Diabetes Among Youths, 2002-2012. N Engl J Med 377: 301.

5. Downie E, Craig ME, Hing S, Cusumano J, Chan AKF, et al. (2011) Continued Reduction in the Prevalence of Retinopathy in Adolescents With Type 1 Diabetes: Role of Insulin Therapy and Glycemic Control. Diabetes Care 34: 2368-2373.

6. National Center for Health Statistics (2018) National hospital discharge and ambulatory surgery data.

7. Shalitin S, Chase HP (2013) Diabetes Technology and Treatment in the Pediatric Age Group. Diabetes Technol Ther 15 Suppl 1: S107-S116.

8. Steineck I, Cederholm J, Eliasson B, Rawshani A, Eeg-Olofsson K, et al. (2015) Insulin Pump Therapy, Multiple Daily Injections, and Cardiovascular Mortality in 18,168 People with Type 1 Diabetes: Observational Study. BMJ 350: h3234.

9. Azmi S, Ferdousi M, Petropoulos IN, Ponirakis G, Fadavi $\mathrm{H}$, et al. (2015) Corneal Confocal Microscopy Shows an Improvement in Small-Fiber Neuropathy in Subjects With Type 1 Diabetes on Continuous Subcutaneous Insulin Infusion Compared With Multiple Daily Injection. Diabetes Care 38: e3-e4.

10. Nabhan ZM, Kreher NC, Greene DM, Eugster EA, Kronenberger W, et al. (2009) A Randomized Prospective Study of Insulin Pump vs. Insulin Injection Therapy in Very Young Children With Type 1 Diabetes: 12-month Glycemic, BMI, and Neurocognitive Outcomes. Pediatr Diabetes 10: 202-208.

11. Kordonouri O, Hartmann R, Danne T (2011) Treatment of Type 1 Diabetes in Children and Adolescents Using Modern Insulin Pumps. Diabetes Res Clin Prac 93 Suppl 1: S118-S124.

12. Brorsson AL, Leksell J, Viklund G, Olinder AL (2013) A Multicentre Randomized Controlled Trial of an Empowerment-Inspired Intervention for Adolescents Starting Continuous Subcutaneous Insulin Infusion--A Study Protocol. BMC Pediatrics 13: 212. 
13. Corney SM, Dukatz T, Rosenblatt S, Harrison B, Murray R, et al. (2012) Comparison of Insulin Pump Therapy (Continuous Subcutaneous Insulin Infusion) to Alternative Methods for Perioperative Glycemic Management in Patients With Planned Postoperative Admissions. J Diabetes Sci Technol 6: 1003-1015.

14. Johnson SR, Cooper MN, Jones TW, Davis EA (2013) Long-term Outcome of Insulin Pump Therapy in Children With Type 1 Diabetes Assessed in a Large Population-Based Case-Control Study. Diabetologia 56: 2392-2400.

15. Skogsberg L, Fors H, Hanas R, Chaplin JE, Lindman E, et al. (2008) Improved Treatment Satisfaction but No Difference in Metabolic Control When Using Continuous Subcutaneous Insulin Infusion vs. Multiple Daily Injections in Children at Onset of Type 1 Diabetes Mellitus. Pediatric diabetes 9: 472-479.

16. Heptulla RA, Allen HF, Gross TM, Reiter EO (2004) Continuous Glucose Monitoring in Children With Type 1 Diabetes: Before and After Insulin Pump Therapy. Pediatr Diabetes 5: 10-15.

17. Papargyri P, Rodriguez SO, Hernandez JJC, Álvarez MTM, Córdova JMR, et al. (2014) An Observational 7-year Study of Continuous Subcutaneous Insulin Infusion for the Treatment of Type 1 Diabetes Mellitus. Endocrinol Nutr 61: 141-146.

18. Mcnally PG, Jowett NI, Kurinczuk JJ, Peck RW, Hearnshaw JR (1988) Lipohypertrophy and Lipoatrophy Complicating Treatment With Highly Purified Bovine and Porcine Insulins. Postgrad Med J 64: 850853.

19. Garg SK, Voelmle MK, Beatson CR, Miller HA, Crew LB, et al. (2011) Use of Continuous Glucose Monitoring in Subjects With Type 1 Diabetes on Multiple Daily Injections Versus Continuous Subcutaneous Insulin Infusion Therapy: A Prospective 6-month Study. Diabetes Care 34: 574-579.

20. American Diabetes Association (2014) Connected for Life.

21. Fox LA, Buckloh LM, Smith SD, Wysocki T, Mauras N (2005) A Randomized Controlled Trial of Insulin Pump Therapy in Young Children With Type 1 Diabetes. Diabetes Care 28: 1277-1281.

22. Hasselmann C, Pecquet C, Bismuth E, Raverdy C, Sola-Gazagnes A, et al. (2013) Continuous Subcutaneous Insulin Infusion Allows Tolerance Induction and Diabetes Treatment in a Type 1 Diabetic Child With Insulin Allergy. Diabetes Metab 39: 174-177.

23. Cope JU, Samuels-Reid JH, Morrison AE (2012) Pediatric Use of Insulin Pump Technology: A Retrospective Study of Adverse Events in Children Ages 1-12 Years. J Diabetes Sci Technol 6: 1053-1059.

24. Hsin-Chieh $\mathrm{Y}$, Brown TT, Maruthur N, Ranasinghe $\mathrm{P}$, Berger $\mathrm{Z}$, et al. (2012) Comparative Effectiveness and Safety of Methods of Insulin Delivery and Glucose Monitoring for Diabetes Mellitus. Ann Intern Med 157: 336-347.
25. Little SA, Leelarathna L, Walkinshaw E, Tan HK, Chapple O, et al. (2014) Recovery of Hypoglycemia Awareness in Long-standing Type 1 Diabetes: A Multicenter $2 \times 2$ Factorial Randomized Controlled Trial Comparing Insulin Pump With Multiple Daily Injections and Continuous With Conventional Glucose Self-Monitoring (HypoCOMPaSS). Diabetes Care 37: 2114-2122.

26. Weintrob N, Schechter A, Benzaquen H, Shalitin S, Lilos P, et al. (2004) Glycemic Patterns Detected by Continuous Subcutaneous Glucose Sensing in Children and Adolescents With Type 1 Diabetes Mellitus Treated by Multiple Daily Injections vs. Continuous Subcutaneous Insulin Infusion. Arch Pediatr Adolesc Med 158: 677-684.

27. Fendler W, Baranowska Al, Mianowska B, Szadkowska A, Mlynarski W (2012) Three-year comparison of subcutaneous insulin pump treatment with multi-daily injections on $\mathrm{HbA1c}$, its variability and hospital burden of children with type 1 diabetes. Acta Diabetol 49: 363-370.

28. Litton J, Rice A, Friedman N, Oden J, Lee MM, et al. (2002) Insulin Pump Therapy in Toddlers and Preschool Children With Type 1 Diabetes Mellitus. J Pediatr 141: 490-495.

29. Bouchonville M, Jaghab J, Duran-Valdez E, Schrader R, Schade D (2014) The Effectiveness and Risks of Programming an Insulin Pump to Counteract the Dawn Phenomenon in Type 1 Diabetes. Endocr Pract: $1-25$

30. Pozzilli $P$, Crinò A, Schiaffini R, Manfrini S, Fioriti E, et al. (2003) A 2-year Pilot Trial of Continuous Subcutaneous Insulin Infusion Versus Intensive Insulin Therapy in Patients With Newly Diagnosed Type 1 Diabetes (IMDIAB 8). Diabetes Technol Ther 5: 965-974.

31. Dost A, Herbst A, Kintzel K, Haberland H, Roth CL, et al. (2007) Shorter Remission Period in Young Versus Older Children with Diabetes Mellitus Type 1. Exper Clin Endocrinol Diabetes 115: 33-37.

32. de Beaufort CE, Houtzagers CM, Bruining GJ, Aarsen RS, den Boer NC, et al. (1989) Continuous Subcutaneous Insulin Infusion (CSII) Versus Conventional Injection Therapy in Newly Diagnosed Diabetic Children: Two-Year Follow-Up of a Randomized, Prospective Trial. Diabetes Med 6: 766-771.

33. Hanaire-Broutin H, Melki V, Bessieres-Lacombe S, Tauber JP (2000) Comparison of Continuous Subcutaneous Insulin Infusion and Multiple Daily Injection Regimens Using Insulin Lispro in Type 1 Diabetic Patients on Intensified Treatment: A Randomized Study. The Study Group for the Development of Pump Therapy in Diabetes. Diabetes Care 23: 1232-1235.

34. The Diabetes Control and Complications Trial/Epidemiology of Diabetes Interventions and Complications Research Group, Lachin JM, Genuth S, Cleary P, Davis MD, et al. (2000) Retinopathy and Nephropathy in Patients with Type 1 Diabetes Four Years After a Trial of Intensive Therapy. N Engl J Med 342: 381-389. 